\title{
Verification of a Clear-Sky Mesoscale Simulation Using Satellite-Derived Surface Temperatures
}

\author{
M. A. Jiménez, A. Mira, J. Cuxart, A. Luque, and S. Alonso \\ Meteorology Group, Departament de Física, Universitat de les Illes Balears, Palma de Mallorca, Spain \\ J. A. Guijarro \\ Meteorological State Agency, Delegación Territorial en Illes Balears, Palma de Mallorca, Spain
}

(Manuscript received 20 November 2007, in final form 17 April 2008)

\begin{abstract}
A mesoscale simulation for Majorca Island is made using the Méso-NH model for a spring night, under a slack synoptic pressure gradient with weak general winds and clear skies. The circulations over and around the island are driven mostly by the locally generated flows, due to the topography and the land-sea thermal contrast. The verification of mesoscale simulations in clear-sky conditions is difficult, especially if the network of stations is not very dense. The main objective of this work is to try to verify the mesoscale simulation using measurements from automatic weather stations and satellite measurements. The model outputs are compared with the available instrumental data and the representativeness of the stations is discussed. Furthermore, complete two-dimensional comparisons are made between the radiative surface temperatures produced by the model and those processed from the National Oceanic and Atmospheric Administration and Meteosat Second Generation (MSG) satellite sensors. The high temporal resolution of the MSG images also allows comparison of the temporal evolutions of the surface temperature between satellite pixels and model grid cells. The procedure permits assessment of the closeness of the simulation to in situ and remote sensing observations. The results of the comparison show that the model is able to reproduce most of the observed patterns, such as intense local cooling or persistent outflows at the largest basins.
\end{abstract}

\section{Introduction}

Verification of clear-sky mesoscale simulations is difficult, because usually the local circulations dominate and data from the weather stations are largely conditioned by local features. The topographical patterns generate circulations that usually follow a diurnal cycle when the synoptic winds are weak. In the nighttime, katabatic flows generated on the slopes of the mountains converge to the valleys and then to the basins (Haiden and Whiteman 2005). These features determine the nocturnal local climatology and knowledge of them is important for some areas of human interest, such as agriculture or dispersion of pollutants.

Except for specially designed experimental campaigns, the observational networks are not dense

Corresponding author address: Maria A. Jiménez, Dpt. Física, Universitat de les Illes Balears, Cra. Valldemossa, km. 7.5, 07122 Palma de Mallorca, Spain.

E-mail: mantonia.jimenez@uib.cat enough to study the details of the local circulations, and many times the stations are placed in locations not very representative of their surroundings (i.e., in towns, in summits, or at the coastline). A convenient alternative is to study the local flows with a mesoscale model run at high vertical and horizontal resolutions, as was done for Majorca Island by Cuxart et al. (2007, hereinafter CJM07). Majorca is the largest island of the Balearic Islands, an archipelago located in the western Mediterranean Sea, $200 \mathrm{~km}$ offshore of the Iberian Peninsula. The island has a characteristic scale of $100 \mathrm{~km}$. In CJM07 the distribution of the flows at the island, basin, and slope scales was studied, together with the identification of the areas where the coldest temperatures took place during a winter night of 1999 when the ABL was stably stratified. An attempt to verify some of the modeled characteristics was made using data from automatic weather stations (AWS) and two National Oceanic and Atmospheric Administration (NOAA) images of the studied night.

Here a more extensive verification for a similar night

DOI: 10.1175/2008MWR2461.1 
is performed, taking advantage of the recent data provided by the Meteosat Second Generation (MSG; Schmetz et al. 2002), launched in 2002. This satellite has larger temporal and spatial resolution than its predecessor Meteosat-7, thus allowing comparison of the model results to the satellite pixel information, both spatially and temporally.

Remote measurements from satellites have been used as a complementary tool to study katabatic flows since Bromwich (1989) used a warm signature on winter thermal infrared (TIR) NOAA images to detect them. Here we use the images to verify the model outputs, taking as the observed field the surface radiative temperature estimated from available satellites (NOAA and MSG). The estimation of land surface temperature from MSG (Dash et al. 2002) is not still fully developed due to the short data availability for the scientific community (at the time of this writing), but some cloudiness studies have been performed that have demonstrated the high utility of these images for model verification (Chaboureau et al. 2000). Other studies involving satellite images are Chevallier and Kelly (2002), in which the European Centre for Medium-Range Weather Forecasts (ECMWF) model is verified against global images focusing on clouds and using similar statistical parameters to those calculated in the present work, and Mathieu et al. (2004), where the French Action de Recherche Petite Echelle Grande Echelle (ARPEGE) boundary layer scheme is evaluated through sea surface temperatures and cloud-top temperatures retrieved from the Advanced Very High Resolution Radiometer (AVHRR) sensor for one month, and point-to-point verification is then performed.

The verification has several difficulties. The NOAA satellite images-which have a resolution of $1 \mathrm{~km}$ at nadir-are available only once or twice per night; the MSG ones are available every $15 \mathrm{~min}$, but have a coarser spatial resolution $-3 \mathrm{~km}$ at nadir. The model is run at a horizontal resolution of $1 \mathrm{~km}$ and has a very high temporal resolution (one field every time step, 3 s). On the other hand, point-to-point verification is conditioned by the location of the AWS. In Majorca most of the stations are very near the coastline or in the mountains, and there are very few stations located inside the large basins. At the mountains or near the coast the point-to-point verification is difficult, since the model provides a value representative of the whole grid box and it is not able to capture properly the peculiarities of the small valleys or the sharp discontinuity at the coastline, as in Prabha et al. (1999). Moreover, contributions from all scales are measured by the AWS, while the model is limited by its horizontal resolution and the characteristics of its parameterizations and its physiographic data fields.

There are many types of methods used in verification, depending on the nature of the forecast, the space-time domain, and the specificity of forecast (Stanski et al. 1989; Jolliffe and Stephenson 2003). For the present study, interest is focused on verification of the forecast of continuous variables. In that case, a large variety of statistical parameters such as the rootmean-square error, the correlation coefficient, and the bias can be computed and all of them can be used to determine the forecast quality (as in Bromwich et al. 2001).

The main objective in this work is to verify a mesoscale simulation for the Island of Majorca (similar to CJM07) under nighttime conditions. To our knowledge, this is the first attempt to verify a mesoscale simulation through comparison of surface temperatures to satellite images. In this paper, the observational data and the characteristics of the simulation are given in the next two sections, whereas the verification process is carried out in section 4 , leading finally to the conclusions.

\section{Observational data}

\section{a. AWS data}

A total of 10 AWSs from the Spanish Weather Service are distributed over Majorca, with measurements of $10-\mathrm{m}$ wind direction and velocity, and 1.5-m temperature, humidity, and atmospheric pressure recorded every $10 \mathrm{~min}$. The wind sensors have a threshold value of $0.5 \mathrm{~m} \mathrm{~s}^{-1}$ and wind speed measurements below this value are not trustworthy. Since AWS data are recorded every $10 \mathrm{~min}$, winds smaller than $0.5 \mathrm{~m} \mathrm{~s}^{-1}$ indicate averages including instants where the wind speed is smaller than this threshold value.

The AWSs are very irregularly distributed (Fig. 1a). Half of the stations are located near the coast, and three at the northern mountain range: one in a summit and the other two in small valleys within the range. Figure $1 \mathrm{~b}$ shows the topography seen by the Méso-NH model, following the slope from the Airport to Cura Mountain (see line in Fig. 1a), at 5- and 1-km resolution. In the same plot these topographies are compared with those obtained from a digital terrain model (DTM) at 100-m resolution. The model uses a smoothed representation of the topography and, besides, the heights of the grid boxes represent the averaged value instead of the point value that an AWS is yielding. The height differences between the actual AWS and the corresponding grid boxes in the model are given in Table 1, and are larger for the AWS located in the Tramuntana range (i.e., Valldemossa, Alfàbia, and Lluc), since the small topo- 
(a)

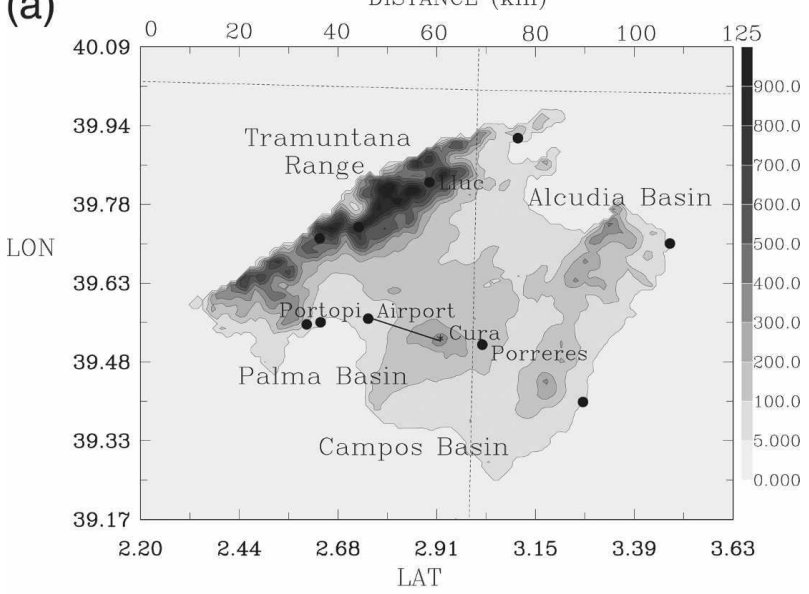

(b)

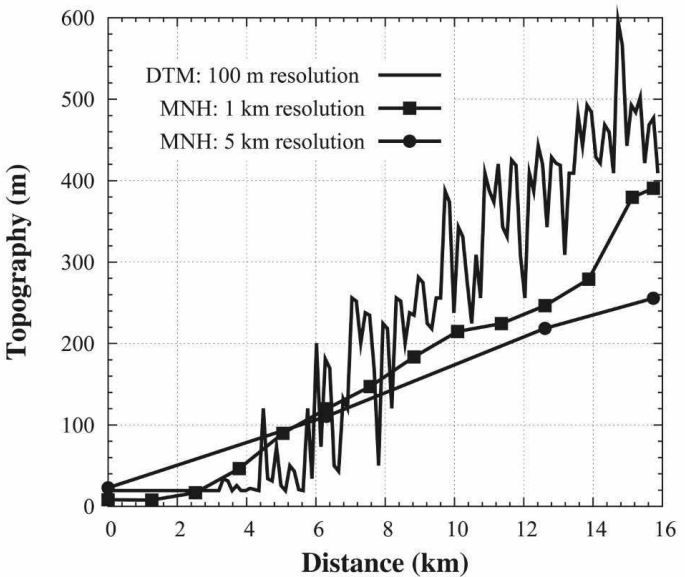

FIG. 1. (a) Topography of the Majorca Island (m) seen by the Méso-NH model at 1-km resolution. The three well-defined basins (Palma, Alcudia, and Campos) are indicated, as well as the location of the 10 AWS (circles). (b) Topography from the Airport to Cura (elevated area in the center) following the line in (a) seen by the model (inner and outer simulated domains) and obtained from a DTM.

graphical features where they are located are not well captured by the model. A similar problem takes place with the AWS near the coastline. To take into account the subgrid information of the land uses, the grid box is partitioned in four main surface types: sea, inland water, towns, and natural and cultivated areas. As a result, at the points close to the coastline, the model gives a value that averages a part of sea and a part of land, whereas the station is located at one side of the discontinuity, making the point-to-point comparison rather unclear for these cases.

\section{b. NOAA imagery}

The NOAA-16 is a polar-orbiting satellite (Kidwell 1998). It provides two images per night in the Balearic
TABLE 1. Comparison between the AWS heights and its modeled values $(\mathrm{m})$.

\begin{tabular}{lrrr}
\hline \multicolumn{1}{c}{ Station } & AWS & Model & AWS - model \\
\hline Lluc & 490 & 544 & -54 \\
Valldemossa & 410 & 557 & -147 \\
Calvià & 60 & 28 & 32 \\
Portopí & 3 & 5 & -2 \\
Alfàbia & 1030 & 769 & 261 \\
Airport & 4 & 10 & -6 \\
Porreres & 120 & 124 & -4 \\
Portocolom & 17 & 2 & 15 \\
Capdepera & 66 & 2 & 64 \\
Pollença & 2 & 37 & -35 \\
\hline
\end{tabular}

Islands $\left(39^{\circ} \mathrm{N}, 3^{\circ} \mathrm{E}\right)$. Its $\mathrm{AVHRR} / 3$ scanning radiometer transmits five channels to the ground (channel 1 in the visible region; 2 in the near-infrared; and 3, 4, and 5 are in the thermal-infrared region). The land surface temperature can be obtained from these data using a splitwindow equation. Here the algorithm used is the one proposed by Coll and Caselles (1997):

$$
\begin{aligned}
T= & T_{4}+\left[1.34+0.39\left(T_{4}-T_{5}\right)\right]\left(T_{4}-T_{5}\right)+0.56 \\
& +\alpha(1-\epsilon)-\beta \Delta \epsilon,
\end{aligned}
$$

where $T$ is the actual land surface radiative temperature (not valid over the sea), $T_{4}$ and $T_{5}$ are the brightness temperatures for channels 4 and 5, $\epsilon$ is the soil emissivity obtained using a daytime image (Valor and Caselles 1996), and $\Delta \epsilon=\epsilon_{4}-\epsilon_{5}$ is the emissivity difference on these channels. It takes into account the absorption and emission of the earth's atmosphere and the nonblackness of the natural emitting surfaces. Finally, $\alpha$ and $\beta$ are coefficients that depend on the atmospheric water vapor content. For the present study, the authors used the Majorca sounding at 0000 UTC 29 April 2005, which yielded the values $\alpha=50 \mathrm{~K}$ and $\beta=120 \mathrm{~K}$.

Two NOAA images are available, one of them at 2125 UTC 28 April and the other one at 0328 UTC 29 April 2005 (local time is equal to UTC time for the Balearic Islands). Both satellite passes see Majorca with a field of view (FOV) angle less than $30^{\circ}$ from the sensor nadir. The preprocessing of the NOAA satellite data consists in applying radiometric, geometric, and atmospheric corrections. The radiometric correction (Di and Runquist 1994) converts the sensor-derived digital numbers to the top-of-the-atmosphere (TOA) reflectances (in optical bands) and brightness temperatures (in thermal bands) using the coefficients included in the AVHRR data files. After the calibration, the images are georeferenced to the Lambert conformal conic map projection system. The atmospheric correction estimates the reflectance at the top of the canopy 
from the TOA reflectance by removing the atmospheric water vapor absorption from the column above Majorca-estimated using the 0000 UTC sounding over Majorca.

\section{c. MSG-1 imagery}

$M S G-1$ is a geostationary satellite of the European meteorological satellite agency (EUMETSAT). The MSG's Spinning Enhanced Visible and Infrared Imager (SEVIRI) provides measurements of the earth disc every $15 \mathrm{~min}$ in 12 spectral channels; channel 9 (10.8 $\mu \mathrm{m})$ gives the best approximation to the actual land surface temperature value, since the transmission around 11 $\mu \mathrm{m}$ is less affected by the atmospheric water vapor than the rest of the spectral intervals, all with wavelengths between 8 and $13 \mu \mathrm{m}$ (Prata et al. 1995).

Values of the MSG channel 9 are used; this channel is provided corrected for radiometric and geometric nonlinearity, before onward distribution to the user (Schmetz et al. 2002). It is important to note that channel 9 brightness temperatures are colder than the real ones because of the atmospheric attenuation, typically 1-2 K (Coll et al. 1994). For the present work, 28 MSG images were used to check the temporal evolution of the surface temperature against (i) AWS temperature and (ii) Méso-NH $1.5 \mathrm{~m}$ and surface temperature, from 1830 UTC 28 April to 0600 UTC 29 April 2005.

\section{Description of the simulation}

Méso-NH (Lafore et al. 1998) is the nonhydrostatic mesoscale atmospheric model of the French research community. The model is intended to be applicable to all scales ranging from large (synoptic) scales to small (large eddy) scales. Its performance for several boundary layer regimes has been tested successfully (Cuxart et al. 2000) and the stable boundary layer has received special attention lately (Jiménez and Cuxart 2005; CJM07).

The characteristics of the simulation setup are identical to the ones described in CJM07 (summarized in their Table 1). The same main parameterizations are used here: a 1.5-order turbulence scheme (Cuxart et al. 2000), the soil scheme Interactions-Soil-BiosphereAtmosphere (ISBA; Noilhan and Planton 1989) and a radiation scheme (Morcrette 1990). Two nested domains are also chosen: the largest covering the Balearic Archipelago with a resolution of $5 \mathrm{~km}$ and the inner covering the Island of Majorca with $1-\mathrm{km}$ resolution. The surface characteristics of the model are taken from the Corine database (Heymann et al. 1994) with a horizontal resolution of $1 \mathrm{~km}$ (Masson et al. 2003).
Figure $1 \mathrm{~b}$ shows the differences between the topography seen by a DTM at $100 \mathrm{~m}$ and how the island topography is seen by the model. The biggest differences are located close to the mountains where, for instance, the valleys smaller than $1 \mathrm{~km}$ are not seen by the model. The vertical resolution is very fine $(3 \mathrm{~m})$ in the near-the-ground layers to properly capture the lowlevel flows. It gradually decreases with height until $5 \mathrm{~m}$ at one hundred meters above the ground level (AGL). From then on, a higher stretching factor is applied so that the resolution at the model top is close to $800 \mathrm{~m}$. A total of 85 vertical levels are used, of which 25 are located within the lowest $100 \mathrm{~m}$. Such a fine resolution near the ground is necessary (Zhong and Fast 2003) to adequately capture the details of the nocturnal lowlevel flows, which often extend only some tens of meters above the ground. However, the price to pay is the use of very small time steps ( $3 \mathrm{~s})$. Analyses provided by the ARPEGE French modeling system (Déqué et al. 1994 ) with a $30-\mathrm{km}$ resolution are used as initial conditions and to force the Méso-NH model at its lateral boundaries each $6 \mathrm{~h}$.

The simulations dominated by the local features might be very sensitive to the representation of the soil-vegetation parameters. The surface energy budget is critically determined by the prescription of the soil and vegetation characteristics, the topography and the soil moisture contents. From the NOAA images the percentage of vegetation cover can be estimated (Fig. $2 a)$. For the date of our simulation the satellites give a value near $30 \%$ for vegetation cover. Instead, the model (Fig. 2b), using monthly climatologically values, prescribes $70 \%$ vegetation cover for this time of April (local spring season). Obviously the surface energy budget would be very different in both situations, with more activity of the vegetation in the second case (higher exchanges of latent heat flux). Moreover the distribution of vegetation is very different between the two sources (Fig. 2). The maximum vegetation cover for the NOAA image is located in the center and north of the island, corresponding to agricultural areas with a very small population. On the contrary, the maximum vegetation cover for the model is located in the northwestern mountain range and has a very homogeneous distribution in the lowlands.

The model is run from 1200 UTC 28 April to 0900 UTC 29 April 2005. This case is chosen to be representative, according to the dynamical climatology study of Raso (1980), who states that more than $40 \%$ of the time weak pressure gradients are present on the Balearic Archipelago, allowing the nocturnal circulations to develop completely. This configuration is similar to the 
(a)

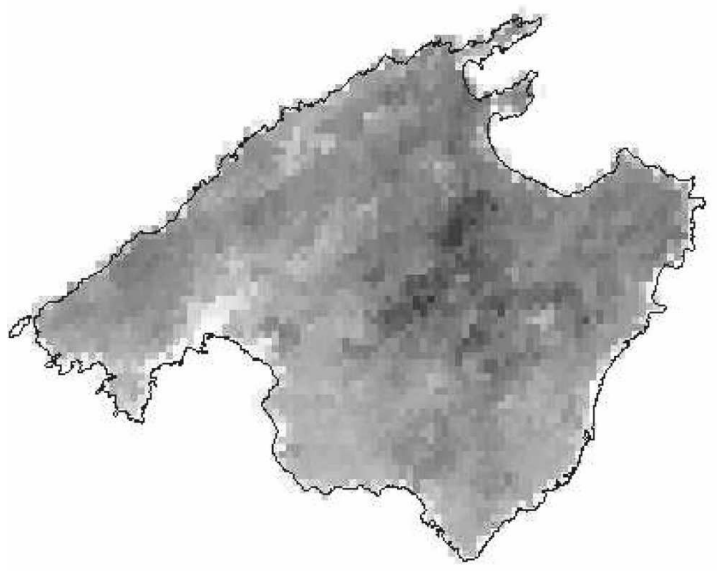

$\frac{d}{9}$

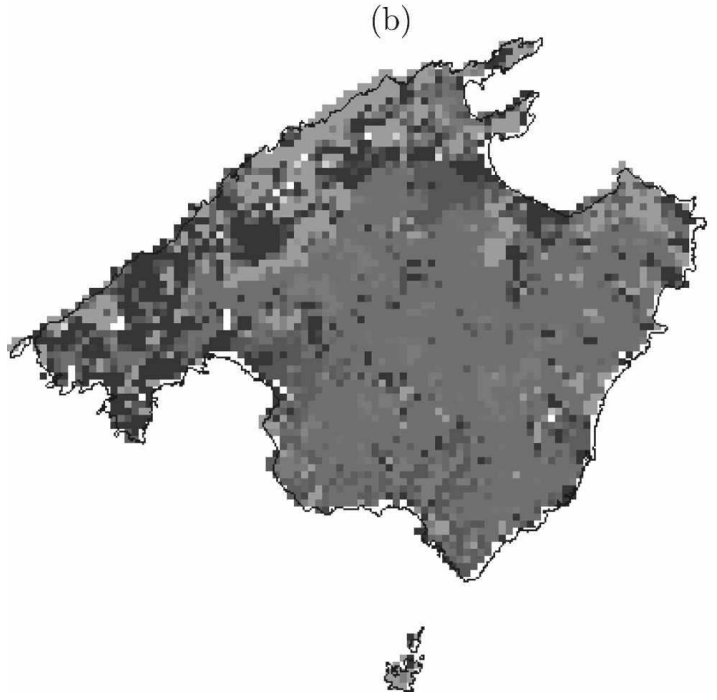

FIG. 2. Percentage of the vegetation cover (a) observed by NOAA and (b) as it is seen by the Méso-NH model.

one in CJM07, and the results are almost identical in both cases. In the daytime, a weak breeze system develops converging from the shores to the center of the island, which becomes warmer than the surrounding sea waters (as in Ramis and Romero 1995).

The simulated regime is a weak synoptic flow from the east that is diverted by the Tramuntana Mountain range (located in the northwestern part of the island). A mesobeta high pressure system is established on the island that allows local circulations to develop. These are mostly at the basin scale during nighttime, when cold air flows downhill and accumulates in the valleys, being pushed offshore by a land-sea breeze. A more detailed description of the typical circulations in this (a)

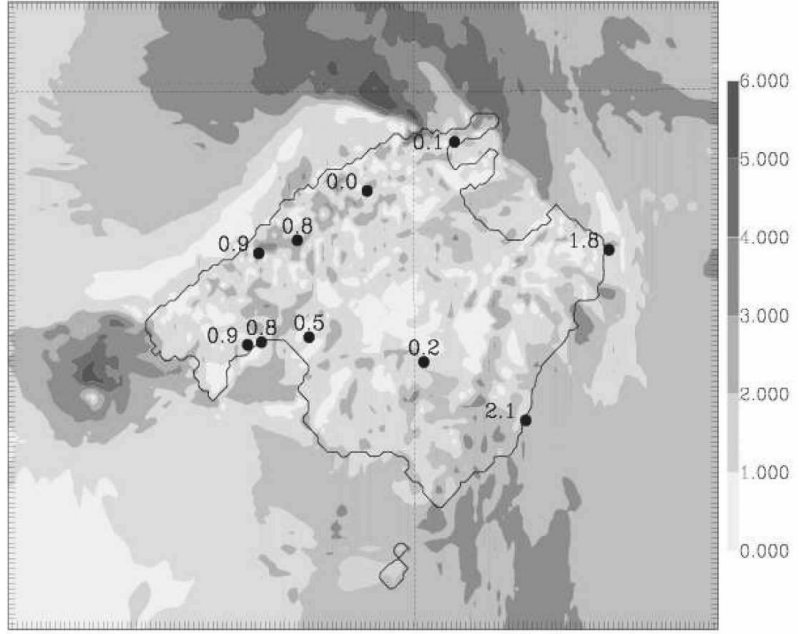

(b)

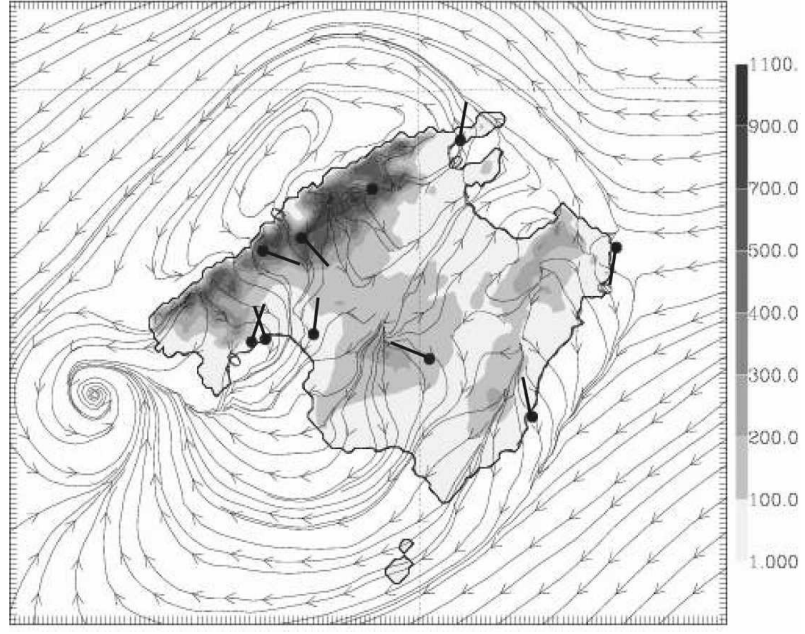

FIG. 3. (a) Modeled and observed 10-m wind velocity ( $\mathrm{m} \mathrm{s}^{-1}$ ) at 0000 UTC; (b) 10-m streamlines and observed wind direction $\left(^{\circ}\right)$ at 0000 UTC over the orography $(\mathrm{m})$. The AWS are indicated in (a) with a point and the observed value aside and in (b) with a bar indicating the wind direction $\left(0^{\circ}\right.$ corresponds to the north direction).

weather configuration can be found in CJM07. Temperature drops near the surface are close to $10 \mathrm{~K}$ along the night and shallow fog areas can form at the end of the night. In Fig. 3 the simulated wind speed and wind direction at 0000 UTC are plotted together with the observed values from AWS and Fig. 4 shows the time evolution of the main meteorological variables compared to two stations in the Palma and the Campos basins (see locations in Fig. 1a). The model is able to reproduce the main observed characteristics, especially the surface cooling and the wind direction. The observed wind speed has values close to the observable threshold $\left(0.5 \mathrm{~m} \mathrm{~s}^{-1}\right)$ and it is weaker than simulated. 

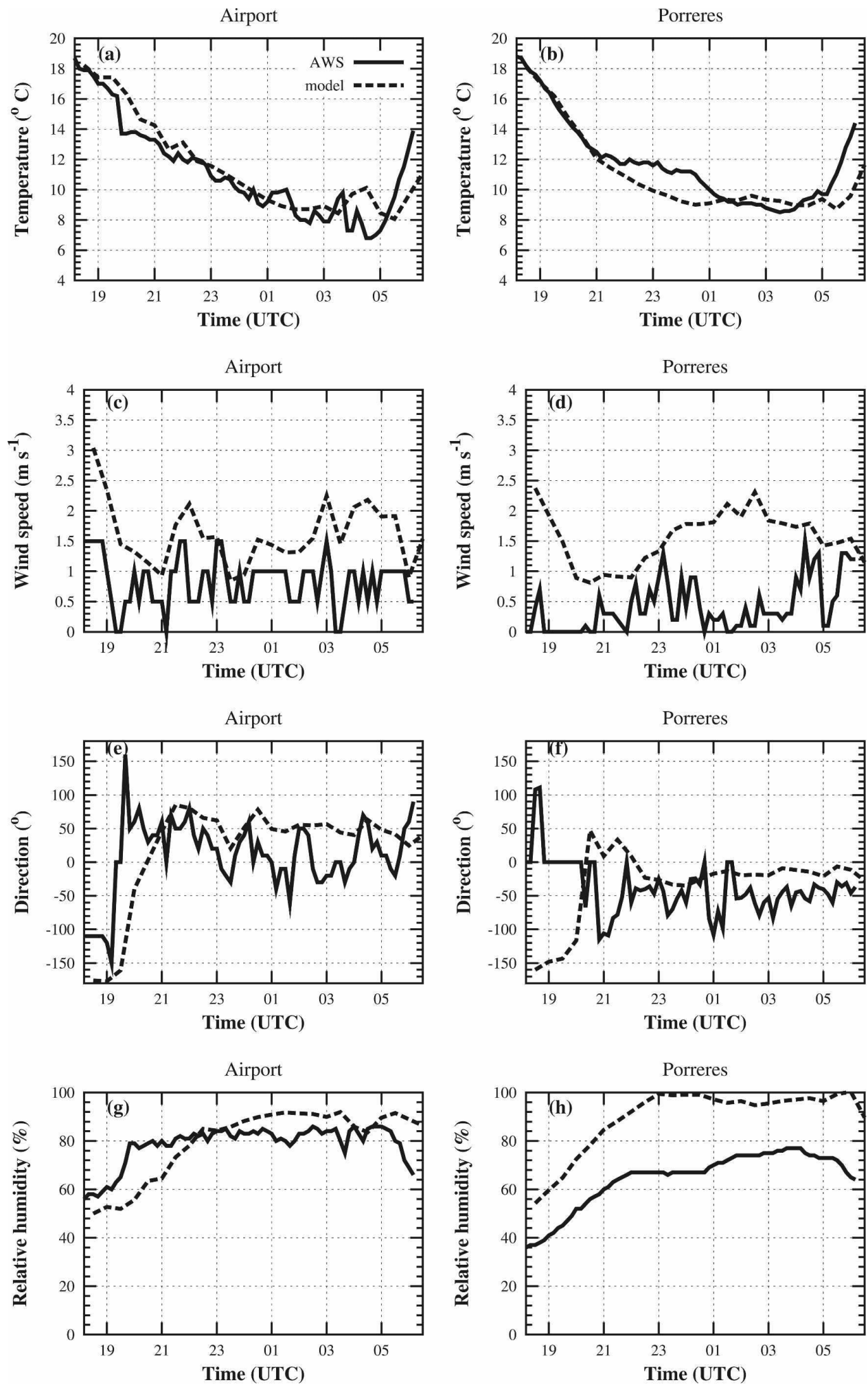

FIG. 4. Time series obtained from the model and the AWS data for the (left) Airport and (right) Porreres stations (see locations in Fig. 1a) for (a), (b) temperature; (c), (d) wind speed; (e), (f) wind direction; and $(\mathrm{g}),(\mathrm{h})$ relative humidity. Model data are constructed with one point each $30 \mathrm{~min}$, and AWS data with one point each $10 \mathrm{~min}$, in both cases taking the temperature and the relative humidity at $1.5 \mathrm{~m}$ and the wind speed at $10 \mathrm{~m}$. 


\section{Verification using the surface radiative temperature}

As described above, the use of the available AWS is insufficient to check the closeness of the simulation to the real conditions. The fact that most of the AWS are near the coast or in mountain valleys makes a direct comparison between model and observation difficult to interpret, as shown in CJM07. Here the NOAA and MSG satellites data are used to perform instantaneous comparisons between complete 2D fields of surface radiative temperature (TSRAD) as estimated by remote sensing methods and as computed by the model. The high temporal resolution of the MSG images allows comparison of the temporal evolution of selected satellite pixels and model grid boxes, using AWS data if available.

TSRAD is presently the only available field given with enough spatial resolution and precision by the meteorological satellites in clear-sky conditions. Estimations of the soil moisture are of lower resolution and precision. The wind field can be obtained for the sea surface or following the motions of the clouds, not applicable for this case, since we are working with the inland fields and without clouds.

\section{a. Spatial verification using NOAA data}

The two available NOAA images are selected for the spatial verification since their resolution is larger than those from MSG and very close to the horizontal resolution used in the inner domain of the simulation (1 $\mathrm{km})$. The first image (2125 UTC) corresponds to the transient part of the night, when the model is still generating the circulations at the basin scale and the katabatic flows are far from steady; it is compared to the 2130 UTC field produced by the model. The second image (0328 UTC) belongs to the steady part of the night, when the slope and basin circulation experience very little changes with time; it is compared to the 0330 UTC model field.

Figure 5 shows the satellite and modeled temperature fields at 2130 (left) and at 0330 UTC (right). The differences in the temperature between NOAA and model are shown in Figs. 5e and 5f at 2130 and 0330 UTC, respectively. Some statistics are given in Table 2. Furthermore, in Fig. 6 the corresponding probability density functions (PDFs) computed from these 2D fields are shown, as well as the PDF computed from MSG data.

At 2130 UTC, the 2D-averaged temperature is more than $1 \mathrm{~K}$ colder than the average of the estimated field from the satellite. The areas colder than, for instance,
$284 \mathrm{~K}$ are larger in the model, especially in the welldefined Palma basin, enclosed by topographical obstacles everywhere except at the sea. This is clearly seen in Fig. 6a where the PDF computed from NOAA data has warmer tails than those computed from MSG or the model. It also shows that the maximum probability of the PDF computed from the model and MSG data are close to each other and with temperature values colder than for the NOAA data. Contrarily to the NOAA image, which is corrected for atmospheric humidity, the MSG image is not and has much less resolution. The standard deviation values (Table 2) for the model and the NOAA image are very close to each other, indicating similar variations of high and low temperatures from the mean.

In contrast, at 0330 UTC, the model and the image are much closer than in the previous case (see Figs. 5c,d and the differences in Fig. 5f), resulting in PDFs computed from satellites and model data closer to each other (see Fig. 6b). The 2D-averaged values differ only $0.5 \mathrm{~K}$ (see Table 2), and the standard deviation has increased in both fields. Both in the 2130 and in the 0330 UTC images, the root-mean-square error (rmse) is close to $2 \mathrm{~K}$. This might indicate that model and satellite have experienced similar evolutions in the cool and relatively warm areas, although at an incorrect speed. Nevertheless, looking at Fig. 5f, some differences persist, especially in some areas of the Palma basin and the eastern foothills of the Tramuntana range, which are both still too cold. This might indicate that the model is deficient in its treatment of the katabatic flows or the representation of the soil-vegetation part, particularly the physiographic databases or the soil moisture contents (see differences in Figs. $1 \mathrm{~b}$ and 2). It must be mentioned here that these areas have a large urban occupation, significantly increased in the last $5 \mathrm{yr}$. Apart from that, the results are also sensitive to chosen parameterizations (e.g., turbulent and/or radiative schemes).

Without regards to the model deficiencies, two different error sources were suspected to be present in these images: a small spatial displacement between model and satellite images due to an imprecision of the geometric adjustment of the satellite data, and an undesired inclusion of sea points into the verification data. To avoid contamination by sea points, surface temperatures above $288 \mathrm{~K}$ (slightly higher than the sea surface temperature given by the model) were excluded from the verification process. In addition, to refine the geometrical adjustment between the satellite and the model images, a slight shift of the model image over the satellite 1 pixel in all directions searching for the best 
(a)

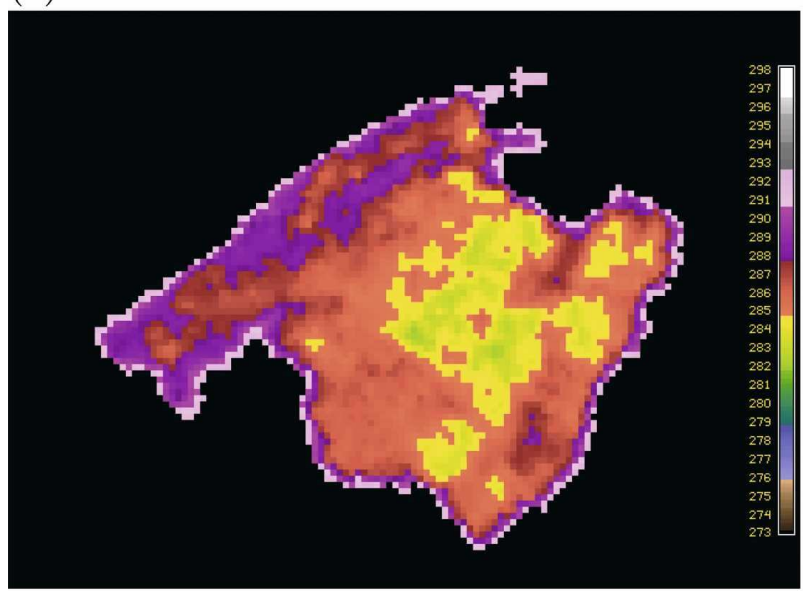

(c)

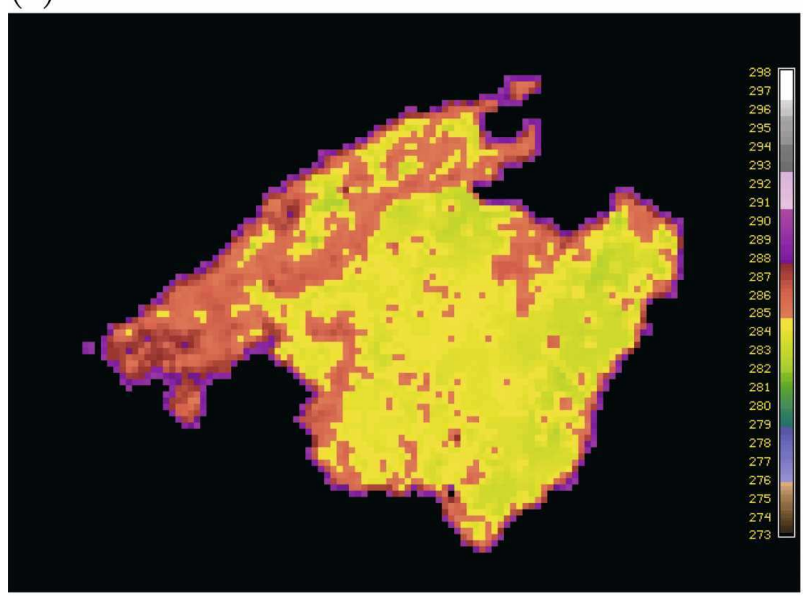

(e)

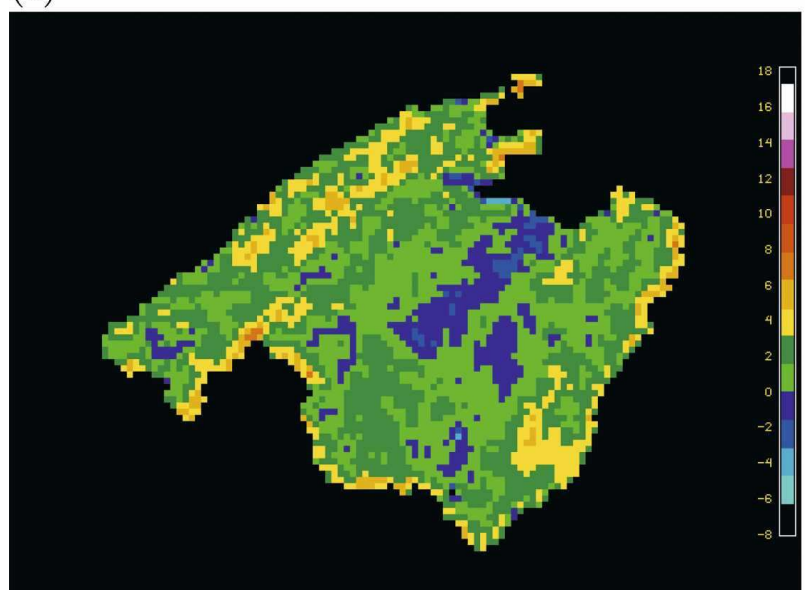

(b)

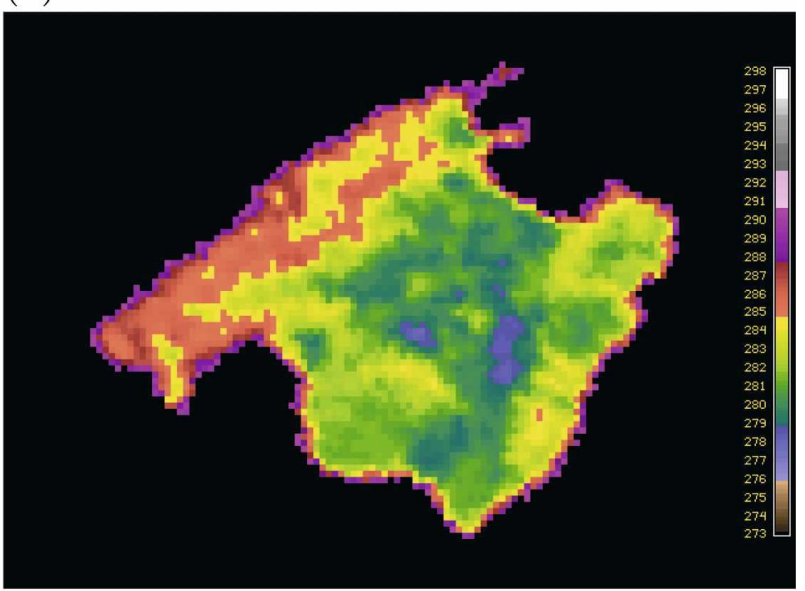

(d)

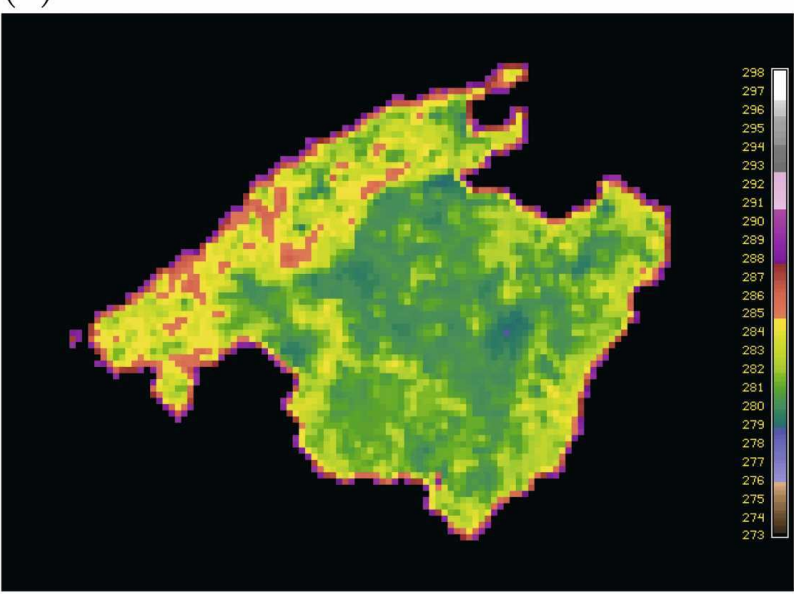

(f)

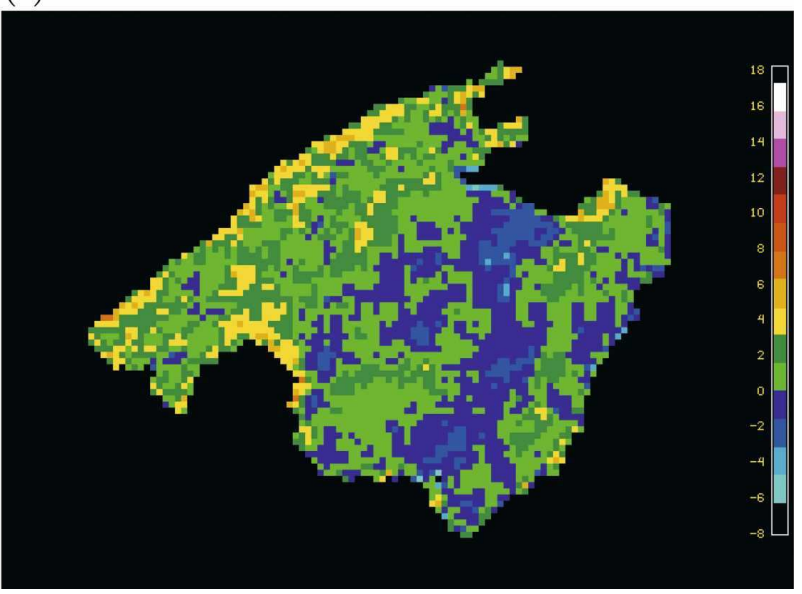

FIG. 5. TSRAD of Majorca Island derived from the NOAA satellite images at (a) 2130 UTC 28 Apr and (b) 0330 UTC 29 Apr 2005. (c), (d) As in (a), (b), but for the Méso-NH model. (e), (f) The difference (TSRAD NOAA - TSRAD $_{\text {model }}$ ) is displayed at 2130 and 0330 UTC, respectively. 
TABLE 2. Statistics computed for NOAA and Méso-NH TSRAD images, where $O$ is observed, $S$ is simulated, and the $d$ index means that the calculations have been performed for a displaced model image. Around 3000 points of the inner domain with no sea contribution are included for the statistics calculations. All parameters are in kelvin except for the correlation coefficient that is a dimensionless index. Shown are mean value $(M)$, BIAS $M_{O}-M_{S}$, root-mean-square error (rmse), standard deviation (STD), and correlation coefficient $(R)$.

\begin{tabular}{|c|c|c|c|c|c|c|c|}
\hline Time & $M_{O}$ & $M_{S}$ & BIAS & RMS & $\mathrm{STD}_{O}$ & $\mathrm{STD}_{S}$ & $R$ \\
\hline 2130 UTC & 286.05 & 284.91 & 1.14 & 2.32 & 1.76 & 1.73 & 0.33 \\
\hline $2130_{d}$ UTC & 286.05 & 284.63 & 1.42 & 2.26 & 1.76 & 1.24 & 0.36 \\
\hline 0330 UTC & 282.61 & 282.18 & 0.43 & 2.08 & 2.24 & 2.22 & 0.59 \\
\hline $0330_{d}$ UTC & 282.61 & 281.98 & 0.63 & 1.76 & 2.24 & 1.81 & 0.69 \\
\hline COOLING & -3.75 & -2.75 & -1.00 & 1.61 & 1.11 & 0.97 & 0.26 \\
\hline $\mathrm{COOLING}_{d}$ & -3.65 & -2.75 & -0.89 & 1.42 & 1.16 & 0.97 & 0.47 \\
\hline
\end{tabular}

correlation between them is performed. As a result of this, a 1-km pixel displacement to the northwest direction improves the correlation coefficient from 0.59 to 0.69 at 0330 UTC (see Table 2).

It is worth noting that the statistical correspondence between the image and the model at 2130 UTC can be improved by filtering both fields to a lower horizontal resolution of $4 \mathrm{~km}$ (not shown), where the correlation coefficient increases from 0.33 to 0.45 , indicating that there is a good correspondence between the modeled and observed large structures, and that the source of the discrepancies lies in the smallest-scale features, probably not well represented in the model. The same exercise at 0330 UTC does not show any significant improvement on the correlation coefficient, already higher than for 2130 UTC.

Finally, if the statistics of the difference fields between 2130 and 0330 UTC are computed (i.e., COOLING in Table 2), it can be seen that the satellite image estimates an averaged fall of temperatures near $4 \mathrm{~K}$, whereas the model only cools about $3 \mathrm{~K}$. However, the estimation from the image can be far from perfect since, for instance, there might be very shallow fog layers at the end of the night (in locations not observable by AWS) or dew (reported in a few observational stations of the island) not accounted in the process, but neither are in the model.

\section{b. Temporal verification using $M S G$ data}

The infrared MSG images are used to represent the temporal evolution of the estimated surface temperature field. The spatial resolution is $3 \mathrm{~km}$ at nadir and for the Balearic archipelago it is $4.45 \mathrm{~km}$ in latitude and $3.12 \mathrm{~km}$ in longitude. In Fig. 7 the evolution of the satellite pixel value and the model grid value of TSRAD are compared, with the two instant NOAA values plotted as a reference. As a complement, the 1.5-m air temperatures as measured by the AWS and as computed by the model are also shown.

\section{1) Grid-SCALE VERIFICATION}

Figure 7 shows the comparison for four different stations (see locations in Fig. 1a). Only one of them (Porreres) is considered to be representative of the basin where it is located (Campos). Another one is at the seashore (Portopí), the other is at a distance of $3 \mathrm{~km}$ to the sea (Airport) and the fourth one is in a small valley within the Tramuntana range (Lluc). Figure 7 plots five quantities that are not equivalent. Two are the computed TSRAD by Méso-NH at 1-km resolution and the MSG channel 9 temperature with $4.5-\mathrm{km}$ resolution and without the correction of the atmospheric attenuation (thus about $1 \mathrm{~K}$ too cold); two others are the time series of the $1.5-\mathrm{m}$ air temperature provided by the AWS and the grid-averaged series for the same area from the first Méso-NH level (at $1.5 \mathrm{~m}$ as well). Finally, the NOAA values for 2125 and 0328 UTC are plotted as dots, since they are assumed to be good estimations of TSRAD. For the TSRAD field only can the comparison of the evolution of the variables be made since any quantitative comparison against the temperature at $1.5 \mathrm{~m}$ would be meaningless. To make a clear comparison, all magnitudes are plotted every $30 \mathrm{~min}$, even if AWS data are available every $10 \mathrm{~min}$.

The evolution of all the quantities for the representative station of Porreres is well captured by the model, as the comparison of TSRAD to the NOAA values and of temperature at $1.5 \mathrm{~m}$ to the AWS shows. The time series of TSRAD computed from the MSG and the model converge at 2300 UTC and stay parallel from then on. The MSG values should be lower and they might be too high because the pixel captures warmer areas around the test grid box. Porreres is located in an area of gentle topography, near the foothills of Cura Mountain (see location in Fig. 1a) and receives a katabatic flow from it all night long. Point values are comparable to average values from the model and satellite, because of the small spatial variability of the area. Thus the model seems to work properly in this area. 

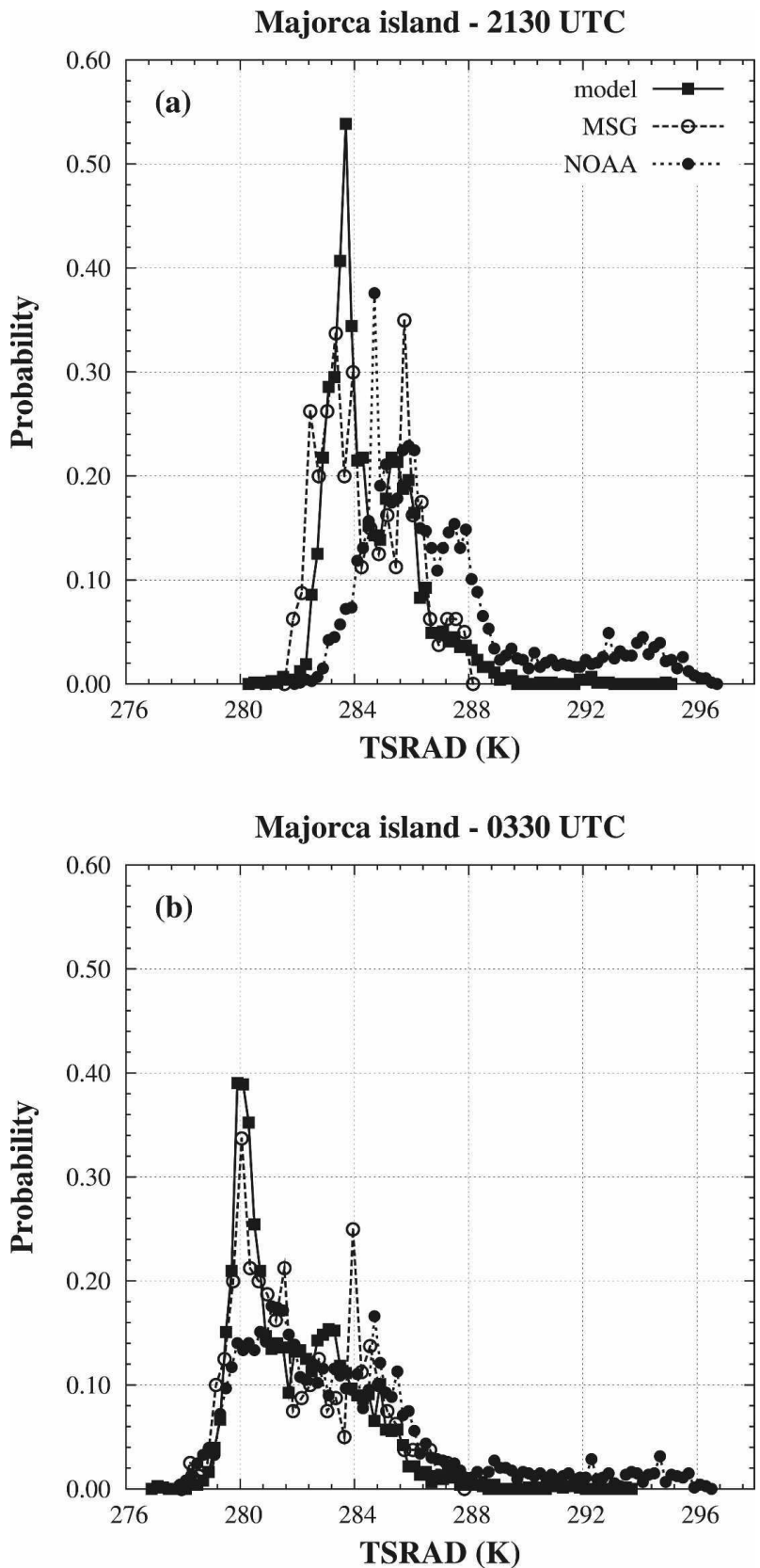

FIG. 6. PDFs of the surface radiative temperature computed from the fields in Fig. 5 (data from model, NOAA, and MSG) at two different instants for Majorca Island at (a) 2130 and (b) 0330 UTC.

The Palma Airport shows the comparison of a land point value, a model grid box of land, and a NOAA and a MSG pixel that have some contribution of the nearby sea. The AWS is located in a small terrain depression, where cold pools usually form. The 1.5-m temperature of the models and the AWS compare well in value and evolution all night long. TSRAD evolution is also well captured, with a sustained cooling amounting $10 \mathrm{~K}$ as seen by the model. MSG decreases only $5 \mathrm{~K}$ because of the contribution of the sea in the pixel.

Two more difficult cases are also shown in Fig. 7, to illustrate how a measurement at an unrepresentative point is not useful for verification purposes. Portopí, at the seashore, is a ventilated area that is strongly influenced by the presence of the warm seawater, an effect that the model is only able to reproduce in an averaged manner, thus overestimating the surface cooling. In Lluc, located in a very small valley at a high altitudenot resolved by the model or the satellites-the observed drop of the air and surface temperatures inside a cold pool is completely missed by the model, but is also wiped out by pixel averaging in the satellites.

\section{2) BASIN-SCALE VERIFICATION}

In Fig. 8 a comparison of the evolution of TSRAD spatial averages computed from the model and the satellite images is shown for the basins of Palma, Campos, and Alcudia (see locations in Fig. 1a). The number of points in each basin (defined by heights below $100 \mathrm{~m}$ for this comparison) are shown in Table 3. For the case of the MSG satellite, this number is small due to its large pixel size. The isle of Majorca has $3600 \mathrm{~km}^{2}$ of which the selected basins have an extent around 325 $\mathrm{km}^{2}$ for Palma, $370 \mathrm{~km}^{2}$ for Alcudia, and $535 \mathrm{~km}^{2}$ for Campos. On the right-hand side in Fig. 8 are the PDFs built from the averaged 2D fields of the surface radiative temperature computed from model and MSG data from 1830 to 0630 UTC over the three basins.

Remembering that the MSG values are about $1 \mathrm{~K}$ too cold and that the NOAA averages are thought to be good estimations of the actual values, it is clear that the model captures the tendency in the Palma basin, but suffers from excessive surface cooling, as already anticipated. The Campos and the Alcudia basins have a very good correspondence between all the methods, showing that the model tends to cool too fast in the beginning of the night, but converges to the actual values after midnight. The sunrise in the model is somewhat delayed in respect to MSG. This might be explained because the very costly radiation scheme (Morcrette 1990) is called by the model every $30 \mathrm{~min}$, but also because the plots are averages over the whole basins for each case and at sunrise some areas are in the shade from where the satellite is located.

For any of the three basins considered, the inspection of the PDFs computed from them shows that the model is able to reproduce the colder areas, but the warmer areas are larger in the model than in MSG (see Figs. $8 \mathrm{~b}, \mathrm{~d}, \mathrm{f})$. This might be because the warm spots are localized in small areas and are wiped out in the pixel average in the MSG images. Also the island has some 


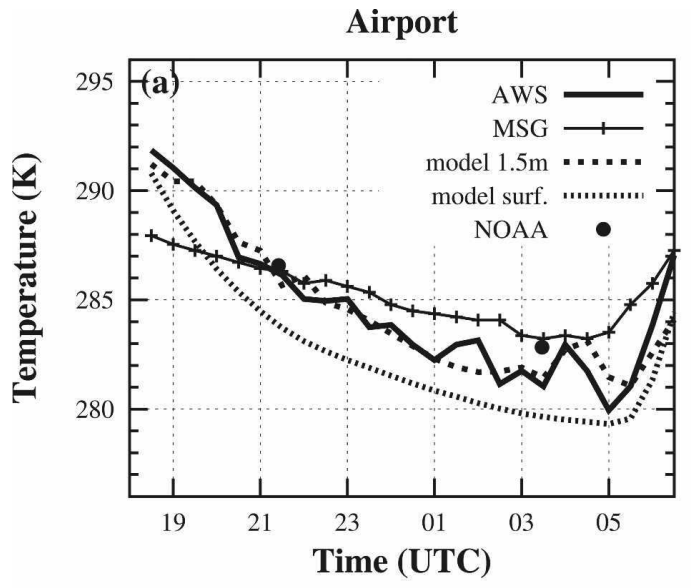

Lluc

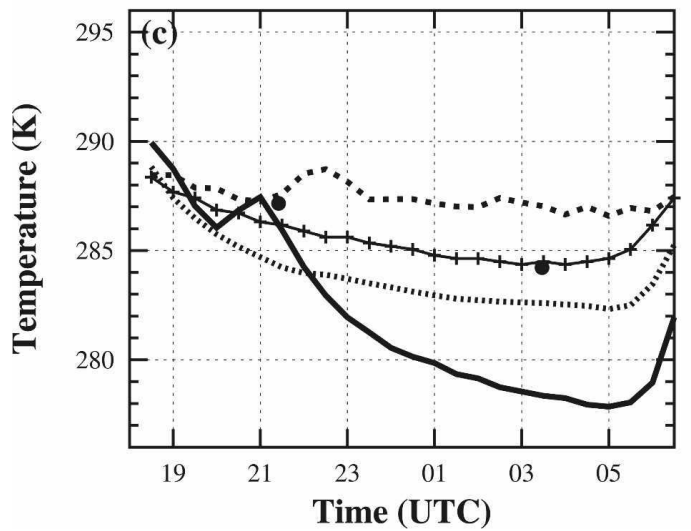

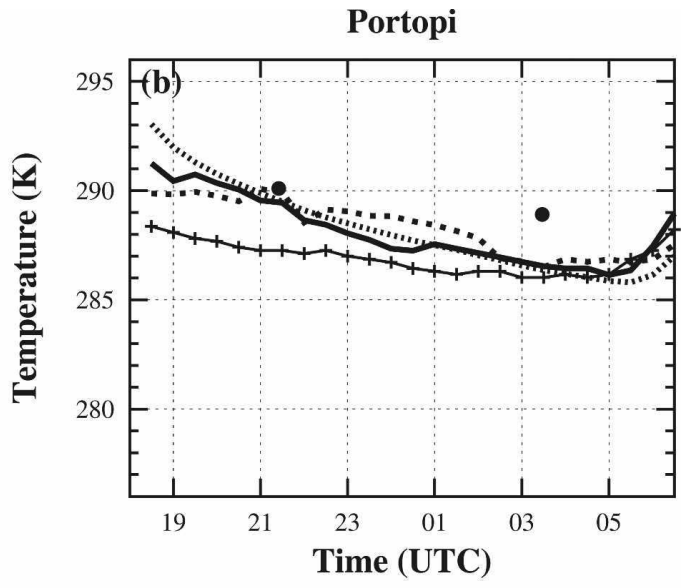

Porreres

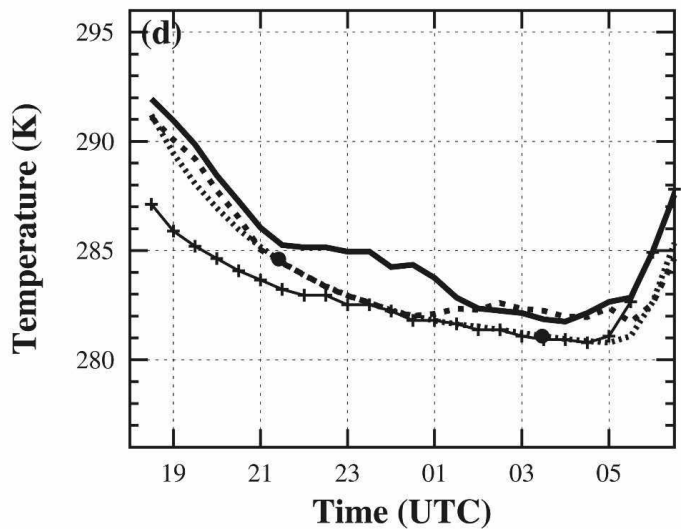

FIG. 7. Time series at four stations in the island (see Fig. 1a): (a) airport, (b) Portopí, (c) Lluc, and (d) Porreres. Different sources have been used: Méso-NH $1.5 \mathrm{~m}$ and surface temperatures, $M S G-1$ channel 9 radiative temperature, and AWS 1.5-m temperature for the period between 1830 UTC 28 Apr and 0630 UTC 29 Apr 2005. Points are the TSRAD values from the NOAA images. To make a clearer comparison, AWS and MSG data are averaged over $30 \mathrm{~min}$ and model data is plotted every $30 \mathrm{~min}$. The radiative temperature derived from channel 9 in MSG is between 1 and $2 \mathrm{~K}$ colder than the real one (Coll et al. 1994).

shallow inland waters that might be treated as deeper by the model physiographical fields. The different geometry, topography, and land use of each basin conditions the shape of the PDFs. The Alcudia basin (see location in Fig. 1a) is the flattest and most homogeneous of the three and shows the best correspondence between the model and satellite, showing that differences may arise in the treatment of the nonhomogeneities in each case. This information is missed when the time series of the averaged values over each basin are plotted for MSG and model data.

\section{Conclusions}

A clear-air mesoscale simulation under a slack pressure gradient has been verified using all available observational information, which includes NOAA and
MSG satellite imagery. The island generates its own system of local winds, and during nighttime the katabatic winds are ubiquitous on the mountain slopes, whereas the center of the basins accumulates cold air that is pushed to the sea by the basin outflows. The wind structures are quasi-stationary during the second part of the night.

The preponderance of the local flows calls into question the method of verifying a simulation against point observations such as AWS. The comparison of model grid-averaged values to measurements of single stations can yield very different results if the station is in a location very different from the average of the grid area, as it is the case for Lluc in the mountains, but can be good otherwise, such as for Porreres in the center of the island.

The satellite images allow comparison of the entire 

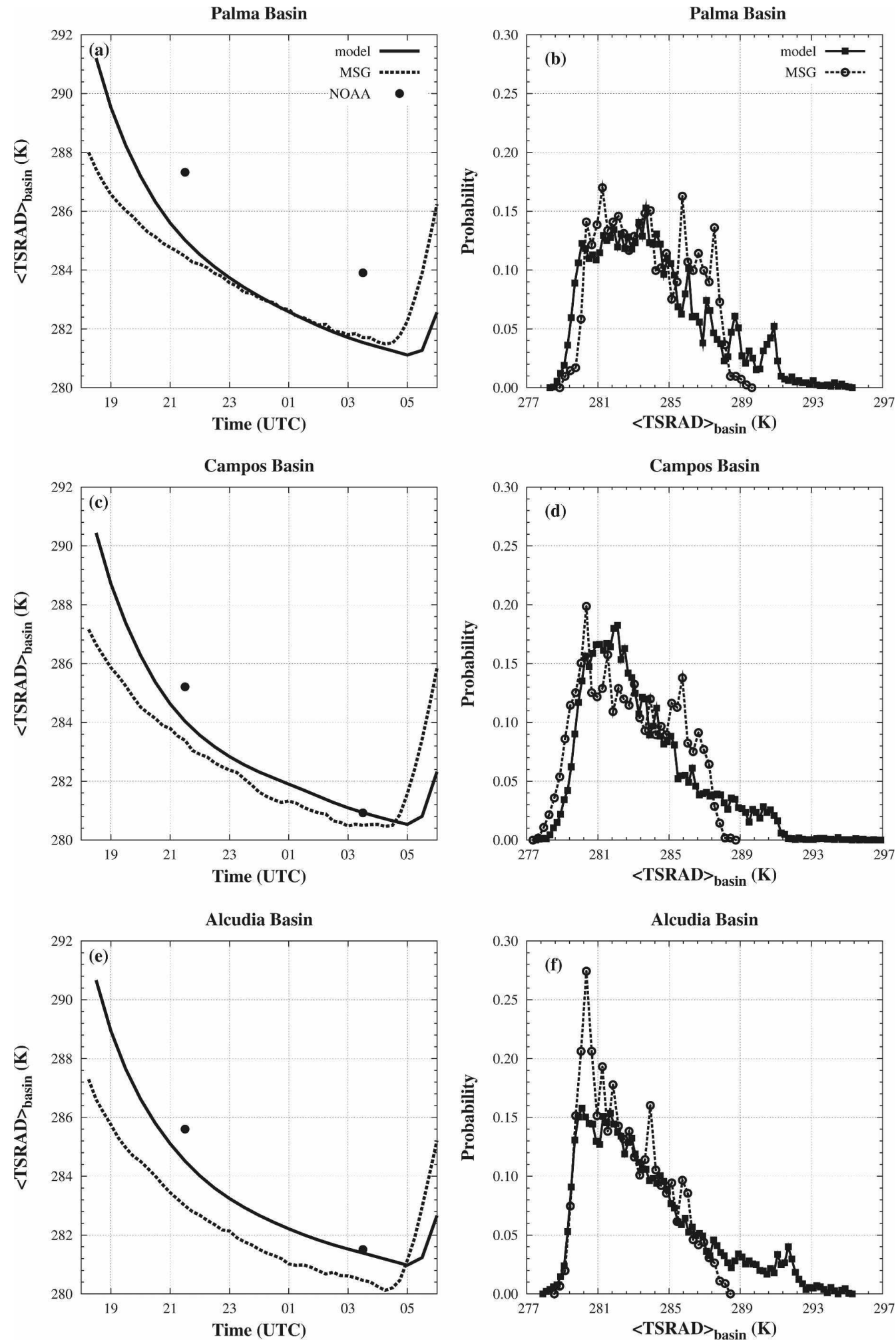

FIG. 8. Surface radiative temperature (K) time series computed by the model (solid line), MSG (dotted line), and NOAA (dots) and the corresponding PDFs computed over the whole night (from 1830 to 0630 UTC of the next day) at (a), (b) Palma basin; (c), (d) Campos basin; and (e), (f) Alcudia basin. See locations in Fig. 1a. The radiative temperature derived from channel 9 in MSG is between 1 and $2 \mathrm{~K}$ colder than the real one (Coll et al. 1994). 
TABLE 3. Number of points included in the basin verification of TSRAD for each data source. According to the model database (1-km resolution) there are 3600 land points for the inner domain.

\begin{tabular}{lccc}
\hline \hline \multicolumn{1}{c}{ Basin } & Model & NOAA & MSG \\
\hline PALMA & 326 & 365 & 28 \\
CAMPOS & 537 & 526 & 38 \\
ALCUDIA & 370 & 379 & 31 \\
\hline
\end{tabular}

area of interest using the surface radiative temperatures, of course being aware of the indetermination of the actual value estimated by the satellite sensors. Pixel-to-grid comparison seems to make sense, especially if the resolutions are similar. It allows computation of 2D statistics and a check of the accuracy of the spatial distribution of values, also opening the door to basin-scale verification. Furthermore, PDFs are computed from the $2 \mathrm{D}$ fields of surface radiative temperature. If a succession of images is available, the time series of the model evolution can be compared to the observed one. In the case studied here, both methods seem to support the good behavior of the Méso-NH model for this particular simulation.

Acknowledgments. We are glad to acknowledge the following: the European Centre for Medium-Range Weather Forecasts (ECMWF) and the Spanish Weather Service (AEMET) for the computing time they allowed, AEMET for the data they provided from AWS, the Méso-NH team in Meteo-France and Laboratoire d'Aérologie, and Universitat de València and EUMETSAT for their help in satellite images. Funding was provided by the Spanish Government (Research Projects REN2003-09435, CGL2005-07105, and CGL2006-12474). Thanks are given to the two anonymous reviewers who provided very useful comments that contributed to the improvement of the paper.

\section{REFERENCES}

Bromwich, D. H., 1989: Satellite analyses of Antarctic katabatic wind behavior. Bull. Amer. Meteor. Soc., 70, 738-748.

— _ J. J. Cassano, T. Klein, G. Heinemann, K. M. Hines, K. Steffen, and J. E. Box, 2001: Mesoscale modeling of katabatic winds over Greenland with the Polar MM5. Mon. Wea. Rev., 129, 2290-2309.

Chaboureau, J.-P., J.-P. Cammas, P. Mascart, J.-P. Pinty, C. Claud, R. Roca, and J.-J. Morcrette, 2000: Evaluation of a cloud system life-cycle simulated by Meso-NH during FASTEX using METEOSAT radiances and TOVS-31 cloud retrievals. Quart. J. Roy. Meteor. Soc., 126, 1735-1750.

Chevallier, F., and G. Kelly, 2002: Model clouds as seen from space: Comparison with geostationary imagery in the $11-\mu \mathrm{m}$ window channel. Mon. Wea. Rev., 130, 712-722.

Coll, C., and V. Caselles, 1997: A split-window algorithm for land surface temperature from advanced very high resolution radiometer data: Validation and algorithm comparison. J. Geophys. Res., 102, 697-713.

, - J. A. Sobrino, and E. Valor, 1994: On the atmospheric dependence of the split-window equation for land surface temperature. Int. J. Remote Sens., 15, 105-122.

Cuxart, J., P. Bougeault, and J.-L. Redelsperger, 2000: A turbulence scheme allowing for mesoscale and large-eddy simulations. Quart. J. Roy. Meteor. Soc., 126, 1-30.

—, M. A. Jiménez, and D. Martínez, 2007: Nocturnal katabatic and mesobeta basin flows on a midlatitude island. Mon. Wea. Rev., 135, 918-932.

Dash, P., F.-M. Göttsche, and F.-S. Olesen, 2002: Potential of MSG for surface temperature and emissivity estimation: Considerations for real-time applications. Int. J. Remote Sens., 23, 4511-4518.

Déqué, M., C. Dreveton, A. Braun, and D. Cariolle, 1994: The ARPEGE/IFS atmosphere model: A contribution to the French community climate modelling. Climate Dyn., 10, 249266.

Di, L., and D. C. Runquist, 1994: A one step algorithm for correction and calibration of AVHRR level $1 \mathrm{~b}$ data. Photogramm. Eng. Remote Sens., 60, 165-171.

Haiden, T., and C. D. Whiteman, 2005: Katabatic flow mechanisms on a low-angle slope. J. Appl. Meteor., 44, 113-126.

Heymann, Y., Ch. Steenmans, G. Croissille, and M. Bossard, 1994: Corine land cover technical guide. Office for Official Publications of the European Communities, Luxembourg, 136 pp.

Jiménez, M. A., and J. Cuxart, 2005: Large-eddy simulations of the stable boundary layer using the standard Kolmogorov theory: Range of applicability. Bound.-Layer Meteor., 115, 241-261.

Jolliffe, I. T., and D. B. Stephenson, 2003: Forecast Verification: $A$ Practitioner's Guide in Atmospheric Science. John Wiley and Sons, $254 \mathrm{pp}$.

Kidwell, K. B., 1998: NOAA polar orbiter data user's guide (TIROS-N, NOAA-6, NOAA-7, NOAA-8, NOAA-9, NOAA-10, NOAA-11, NOAA-12, NOAA-13, and NOAA14). [Available online at http://www2.ncdc.noaa.gov/docs/ podug/index.htm.]

Lafore, J. P., and Coauthors, 1998: The Meso-NH atmospheric simulation system. Part I: Adiabatic formulation and control simulation. Ann. Geophys., 16, 90-109.

Masson, V., J.-L. Champeaux, F. Chauvin, C. Meriguet, and R. Lacaze, 2003: A global database of land surface parameters at $1-\mathrm{km}$ resolution in meteorological and climate models. $\mathrm{J}$. Climate, 16, 1261-1282.

Mathieu, A., A. Lahellec, and A. Weill, 2004: Evaluation of a numerical weather forecast model using boundary layer cloud-top temperature retrieved from AVHRR. Mon. Wea. Rev., 132, 915-928.

Morcrette, J.-J., 1990: Impact of changes to the radiation transfer parameterizations plus cloud optical properties in the ECMWF model. Mon. Wea. Rev., 118, 847-873.

Noilhan, J., and S. Planton, 1989: A simple parameterization of land surface processes for meteorological models. Mon. Wea. Rev., 117, 536-549.

Prabha, T. V., R. Venkatesan, and V. Sitaraman, 1999: Simulation of meteorological fields over a land-water-land terrain and comparison with observations. Bound.-Layer Meteor., 91, 227-257.

Prata, A. J., V. Caselles, C. Coll, J. A. Sobrino, and C. Ottlé, 1995: 
Thermal remote sensing of land surface temperature from satellites: Current status and future prospects. Remote Sens. Environ., 12, 175-224.

Ramis, C., and R. Romero, 1995: A first numerical simulation of the development and structure of the sea breeze in the island of Mallorca. Ann. Geophys., 13, 981-994.

Raso, M., 1980: El clima de Baleares. Summary of Ph.D. thesis, Universitat de Barcelona, Barcelona, Spain, 55 pp.

Schmetz, J., P. Pili, S. Tjemkes, D. Just, J. Kerkmann, S. Rota, and A. Ratier, 2002: An introduction to Meteosat Second Generation (MSG). Bull. Amer. Meteor. Soc., 83, 977-992.
Stanski, H. R., L. J. Wilson, and W. R. Burrows, 1989: Survey of common verification methods in meteorology. World Weather Watch Tech. Rep. 8, WMO/TD-358, WMO, Geneva, Switzerland, 114 pp.

Valor, E., and V. Caselles, 1996: Mapping land surface emissivity from NDVI: Application to European, African and South American areas. Remote Sens. Environ., 57, 167-184.

Zhong, S., and J. D. Fast, 2003: An evaluation of MM5, RAMS, and Meso Eta at sub-kilometer resolution using VTMX field campaign data in the Salt Lake Valley. Mon. Wea. Rev., 131, 1301-1322. 